\title{
Retraction Note: Comparison of $0.05 \%$ cyclosporine and 3\% diquafosol solution for dry eye patients: a randomized, blinded, multicenter clinical trial
}

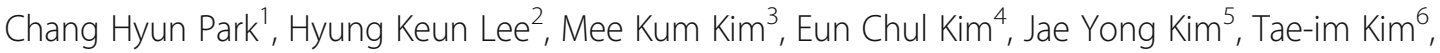 \\ Hong Kyun Kim ${ }^{7}$, Jong Suk Song ${ }^{8}$, Kyung Chul Yoon ${ }^{9}$, Do Hyung Lee ${ }^{10}$, Tae-Young Chung ${ }^{11}$, \\ Chul Young Choi ${ }^{12}$ and Hyun Seung Kim ${ }^{1 *}$
}

\section{Correction to: BMC Ophthalmol (2019) 19:131 https://doi.org/10.1186/s12886-019-1136-8}

The editor has retracted this article [1]. In the accompanying trial registry [2] the authors stated that they conducted three separate arms of this clinical trial. The article only reports the results of two of the arms. The data and the results of this article are therefore unreliable. Additionally, there is considerable overlap with a previously published article by the same authors [3].

**All authors agree to this retraction

\section{Author details}

'Department of Ophthalmology, Yeouido St. Mary's Hospital, College of Medicine, The Catholic University of Korea, 10, 63-ro, Yeongdeungpo-gu, Seoul 07345, South Korea. ${ }^{2}$ The Institute of Vision Research, Department of Ophthalmology, Gangnam Severance Hospital, Yonsei University College of Medicine, Seoul, South Korea. ${ }^{3}$ Department of Ophthalmology, Seoul National University Hospital, Seoul National University College of Medicine, Seoul, South Korea. ${ }^{4}$ Department of Ophthalmology, Bucheon St. Mary's Hospital, College of Medicine, The Catholic University of Korea, Bucheon, South Korea. ${ }^{5}$ Department of Ophthalmology, Asan Medical Center, University of Ulsan College of Medicine, Seoul, South Korea. ${ }^{6}$ The Institute of Vision Research, Department of Ophthalmology, Severance Hospital, Yonsei
University College of Medicine, Seoul, South Korea. ${ }^{7}$ Department of Ophthalmology, Kyungpook National University School of Medicine, Daegu, South Korea. ${ }^{8}$ Department of Ophthalmology, Korea University College of Medicine, Seoul, South Korea. ${ }^{9}$ Department of Ophthalmology, Chonnam National University Medical School, Gwangju, South Korea. ${ }^{10}$ Department of Ophthalmology, Ilsan Paik Hospital, Inje University College of Medicine, Goyang, South Korea. ${ }^{11}$ Department of Ophthalmology, Samsung Medical Center, Sungkyunkwan University School of Medicine, Seoul, South Korea.

${ }^{12}$ Department of Ophthalmology, Kangbuk Samsung Hospital,

Sungkyunkwan University School of Medicine, Seoul, South Korea.

Published online: 23 June 2020

Reference

1. Park, et al. Comparison of $0.05 \%$ cyclosporine and 3\% diquafosol solution for dry eye patients: a randomized, blinded, multicenter clinical trial. BMC Ophthalmol. 2019;19:131. https://doi.org/10.1186/s12886-019-1136-8. 2. https://cris.nih.go.kr/cris/en/search/search_result_st01.jsp?seq=6936.

3. Park CH, Kim MK, Kim EC, Kim JY, Kim TI, Kim HK, Song JS, Yoon KC, Lee DH, Lee HK, Chung TY, Choi CY, Kim HS. Efficacy of Topical Cyclosporine Nanoemulsion 0.05\% Compared with Topical Cyclosporine Emulsion 0.05\% and Diquafosol 3\% in Dry Eye. Korean J Ophthalmol. 2019;33(4):343-52. https:// doi.org/10.3341/kjo.2018.0116.
The original article can be found online at https://doi.org/10.1186/s12886019-1136-8.

*Correspondence: sara514@catholic.ac.kr

'Department of Ophthalmology, Yeouido St. Mary's Hospital, College of Medicine, The Catholic University of Korea, 10, 63-ro, Yeongdeungpo-gu, Seoul 07345, South Korea

Full list of author information is available at the end of the article

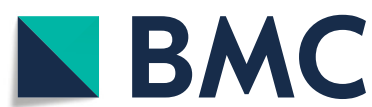

(c) The Author(s). 2020 Open Access This article is licensed under a Creative Commons Attribution 4.0 International License, which permits use, sharing, adaptation, distribution and reproduction in any medium or format, as long as you give appropriate credit to the original author(s) and the source, provide a link to the Creative Commons licence, and indicate if changes were made. The images or other third party material in this article are included in the article's Creative Commons licence, unless indicated otherwise in a credit line to the material. If material is not included in the article's Creative Commons licence and your intended use is not permitted by statutory regulation or exceeds the permitted use, you will need to obtain permission directly from the copyright holder. To view a copy of this licence, visit http://creativecommons.org/licenses/by/4.0/ The Creative Commons Public Domain Dedication waiver (http://creativecommons.org/publicdomain/zero/1.0/) applies to the data made available in this article, unless otherwise stated in a credit line to the data. 